\title{
Primate adaptations and evolution in the southern African Rift Valley
}

René Bobe ${ }^{1,2,3}$

Felipe I. Martínez 4

Susana Carvalho $1,2,3,5$

${ }^{1}$ Gorongosa National Park, Sofala, Mozambique

2 Primate Models for Behavioural Evolution Lab, Institute of Cognitive \& Evolutionary Anthropology, School of Anthropology, University of Oxford, Oxford, UK

${ }^{3}$ Interdisciplinary Centre for Archaeology and Evolution of Human Behaviour (ICArEHB), Universidade do Algarve, Faro, Portugal

${ }^{4}$ School of Anthropology, Faculty of Social Sciences, Pontificia Universidad Católica de Chile, Santiago, Chile

${ }^{5}$ Centre for Functional Ecology, University of Coimbra, Coimbra, Portugal

\section{Introduction and Background}

Gorongosa National Park in central Mozambique offers an unparalleled setting for the study of primate adaptations to complex and highly dynamic environments. Located the southern end of the East African Rift System, Gorongosa hosts a mosaic of forests, woodlands, grasslands, swamps, rivers, and a major lake, Lake Urema, which fluctuates extensively with the seasonal cycles (Figures 1, 2). ${ }^{1}$ Renowned biologist E.O. Wilson has described Gorongosa as "ecologically the most diverse park in the world". ${ }^{2}$ The park is home to five species of nonhuman primates, among them 219 troops of baboons, ${ }^{3}$ whose phenotypic diversity suggests an extended history of admixture between chacmas (Papio ursinus) and yellow baboons (P. cynocephalus) (Figure 3). ${ }^{4}$ With its dynamic mix of environments in the African Rift Valley, and highly adaptable primates, Gorongosa brings to mind the vegetation mosaics in which Pliocene and Pleistocene hominins evolved. ${ }^{5}$

Gorongosa thus provided an ideal setting to bring together a broad interdisciplinary group of scientists to discuss "New perspectives on primate adaptations to complex environments and implications for early human evolution." The occasion was a workshop funded by the WennerGren Foundation and hosted by Gorongosa National Park on 23-25 July 2019. The Wenner-Gren Foundation has sponsored about 165 symposia and workshops over the past 67 years, but this 
was only the third time such an event was held in Africa. The workshop included 36 researchers and students (from 20 institutions in 11 countries) with expertise in primatology, zoology, natural history, ecology, botany, genetics, genomics, paleontology, paleoanthropology, archeology, and geology (Figure 4). The event was open to the public, so researchers, students, and staff working in the park, among them many young Mozambicans, attended the workshop and participated in the discussions. Holding such an event in Mozambique was a milestone for a country with great potential in primatology, paleontology, and paleoanthropology, and allowed Mozambican scholars and students to establish new collaborations for future research and training.

\section{Key questions}

The central aim of the workshop was to set new directions for future theoretical and empirical research on primate adaptations to complex environments. The objective was to shed light on three interrelated questions at the interface of primatology, genetics, and paleoanthropology: 1) Are there identifiable behavioural patterns in primate responses to complex and dynamic environmental conditions? 2) How can we use studies of population structure and interpopulation genetic introgression in wide-ranging primates to understand similar processes in hominin evolution? 3) How can we best integrate new concepts and insights from the study of living primates with a better understanding of hominin evolution and its environmental context?

\section{The Paleo-Primate Project Gorongosa}

The workshop opened with an introduction to Gorongosa National Park by Marc Stalmans, the Director of Scientific Services, who described Gorongosa's mosaic habitats as miombo woodlands, tall limestone gorge forests, Combretum open woodlands, Acacia woodlands, as well as extensive edaphic and secondary grasslands, with the highly dynamic Lake Urema at the heart of the park, fed by major rivers from Mount Gorongosa on the western shoulder of the 
Rift Valley. Rising up to 1863 m, Mount Gorongosa itself is an ecological island of Afromontane rainforest, with a highly endemic flora and fauna. After Mozambique's devastating civil war (1977-1992), the park has been undergoing a highly successful wildlife restoration program and a renaissance of research. ${ }^{6-8}$ It is in this context that in 2016 Susana Carvalho launched the longterm Paleo-Primate Project with the overarching goal of understanding the evolutionary history of the region, with a focus on living primates, as well as archeological and paleontological research. At the workshop, Carvalho discussed how this project integrates studies of modern primate behaviour, genetics, and morphology, with new archeological excavations in Gorongosa's extensive karstic system, as well as new Miocene fossil sites on the eastern shoulder of the rift (Figure 1). ${ }^{9}$ Carvalho and colleagues saw the potential to focus on baboon behavior to learn more broadly about the processes by which primates adapt to complex and dynamic conditions, and about behavioral innovations that might emerge under particular ecological pressures. For example, one of the effects of the civil war was a severe decline of the park's carnivore communities, but lions are making a significant recovery in population size, leopards are returning, and wild dogs have been successfully reintroduced (Figures 5, 6). Thus, Gorongosa now offers a natural experiment to document how primate behaviour varies with different levels of predation pressure. Researchers are also documenting predation events and carrying out osteological surveys and collections across different environments. Jacinto Mathe, a young Mozambican scholar, discussed the first results of this neotaphonomic approach, and demonstrated that there are intriguing differences in mammalian abundances between bone surveys and aerial surveys of living animals. The bone surveys may be better at capturing species that are difficult to see and count from the air, and thus provide a supplementary method to estimate faunal distributions and abundance. These opening presentations were followed by in-depth talks and discussions of the three main themes/questions of the workshop.

\section{Theme 1: primate behaviour in complex environments}


Baboons provide a striking example of an anthropoid primate that is widely distributed, ecologically adaptable, and behaviorally flexible. ${ }^{10}$ Baboon research in Africa has a long and distinguished history, ${ }^{11-14}$ but until now the baboons of Gorongosa had never been studied, even though with 219 troops (and many thousands of individuals), the park likely holds one of the highest concentrations of these primates in Africa. A series of presentations introduced the workshop participants to the emerging work on Gorongosa baboons. Dora Biro discussed the team's work on possible cultural behaviors in relation to bark stripping; Lynn Lewis-Bevan discussed social and ecological factors in relation to baboon ranging patterns in a floodplain environment, and Philippa Hammond presented work on the changing landscapes of fear in a troop of woodland baboons by analyzing vocalizations and vigilance patterns. The concept of landscapes of fear affecting the ranging and behavior of primates was discussed in depth by Russell Hill based on his team's work at the Lajuma Research Centre in the Soutpansberg Mountains of South Africa. ${ }^{15,16}$

The workshop was privileged to have representatives from some of the longest ongoing baboon study sites in Africa. Susan Alberts brought to bear the decades of research at Amboseli National Park in Kenya, where baboons were first studied in $1963,{ }^{12,17}$ and Anthony Collins brought to the discussion his nearly 50 years of experience at Gombe National Park in Tanzania, where baboons share their habitats with chimpanzees. It is only through long-term studies such as these that researchers can study evolutionary processes in action. At Amboseli, for example, we have learned that females with long life spans have overall higher offspring survival than females with shorter life spans.

The diversity of habitats in which baboons live was highlighted by Alecia Carter's study of baboons in the edges of the Namib Desert at the Tsaobis Nature Park in Namibia, where she has documented information acquisition through dynamic social networks. ${ }^{18}$ Variation in baboon social systems was eloquently presented by Julia Fischer, who discussed the nested multi-level society of Guinea baboons from the "neglected West" ${ }^{19}$ Fischer's work at Niokolo Koba National Park in Senegal reveals that the Guinea baboon social system is in some 
fundamental features similar to that of hamadryas baboons. Guinea baboons are organized in reproductive units consisting of one male with several females and their young, with several of these reproductive units forming a "party", and several parties forming a "gang". Gangs are formed by a core of closely related males, and females tend to transfer between gangs. Compared to other baboon species, Guinea baboons show lower levels of male-male aggressiveness, and compared to hamadryas they have more female freedom.

Thus, baboons took center stage at the workshop, and not only as a topic of discussions: during the course of the meetings, baboons would often peek into the lecture theatre or jump across its roof, above the participants' heads. We had the rare opportunity of discussing these amazing primates with renowned baboon specialists while observing baboon behavior right before our eyes.

\section{Theme 2: primate genetics/genomics and hybridization}

Baboons have become important in studies of the evolutionary processes that lead to population divergence, speciation, and hybridization in primates. ${ }^{10,20-22}$ Adding to the social complexity inherent in primate societies and the environmental complexity of the Gorongosa ecosystem is the apparently mixed origin of the Gorongosa baboons. Our recent work indicates that Gorongosa harbors chacma baboons descended from populations that experienced some historical gene flow from yellow and/or Kinda baboons. Whether gene flow is still ongoing is an urgent research question. Felipe Martínez and Thomas Püschel presented their study on the morphological variation in Gorongosa baboon populations. Gorongosa baboons exhibit features that are diagnostic of the grayfooted chacma baboon (Papio ursinus griseipes), but they also exhibit features frequently seen in yellow and Kinda baboons. The morphometric analysis of the skull shows that their phenotype is a mosaic of features from yellow and grayfooted baboons

23. Maria Joana Ferreira da Silva and colleagues presented their study on Gorongosa baboon population structure and genetic diversity estimates using non-invasive DNA samples and mtDNA and STR genetic markers. At the mtDNA level, Gorongosa baboons fall within the 
northern chacma clade, formed by grayfooted baboon populations (from Namibia and Botswana). ${ }^{24}$ Using STR data, da Silva and colleagues estimated high levels of genetic diversity, comparable to that of yellow baboons and Papio hybrid zones elsewhere. They also found a gradient of genetic variation from Gorongosa to the Zambezi River (located $150 \mathrm{~km}$ to the north). Cristian Capelli and colleagues presented a preliminary analysis of the first baboon whole-genome from Gorongosa indicating high nuclear diversity. Further analyses will reveal if, when, and to what extent baboons in the region experienced gene flow with other chacma groups and hybridization with other baboon species.

Dietmar Zinner discussed the phylogeography of African savanna monkeys. The historical dynamics of savanna habitats explain the geographic pattern of many African species. In the case of baboons, speciation started around $2 \mathrm{Ma}$ but gene flow across lineages occurred multiple times. ${ }^{22}$ Papio mtDNA lineages indicate a north-south split. The oldest mtDNA lineages are found in southern Africa and, thus, the range expansion of baboons occurred from south to north in agreement with the fossil record. ${ }^{25}$ In turn, the distribution of baboon mtDNA lineages correlates well with geography but not taxonomy. The incongruence between nuclear and mtDNA is the result of several episodes of male-driven, introgressive hybridization within Papio. ${ }^{24,26}$ Clifford Jolly discussed the evolutionary origins of male philopatry in hamadryas and Guinea (H-G) baboons in contrast to female philopatry in chacma, olive, Kinda, and yellow (COKY) baboons. Jolly argues that male philopatry is fundamental to other behavioral traits and a basic precondition for the evolution of the multi-level societies. It was not an ecological adaptation but rather an adaptation to the rapid expansion of the proto $\mathrm{H}-\mathrm{G}$ populations. In this scenario, the population's geographical range was expanding south to north as troops at the front edge increased in size, fissioned, and sent colonists forward into open territory. The lack of troops beyond the frontier would have favored males that stayed and attempted to breed in their natal group. This 'frontier' hypothesis for the evolution of large and substructured groups in northern baboons implies that male philopatry was a feature of the common ancestor of all northern baboons, but only in hamadryas and Guinea baboons has it survived later introgression, principally by male olive baboons ( $P$. anubis). 


\section{Theme 3: hominin paleoenvironments}

Research on the environments of early hominins emphasizes the importance of dynamic and heterogeneous ecosystems as the fundamental substrate on which key hominin adaptations emerged in Africa. ${ }^{27,28}$ The workshop had several presentations and lively discussions on this topic. In a splendid talk with the title of "Mozambique in island Africa", Jonathan Kingdon described "the big picture" and the role of major basins, with the Congo basin and a series of lesser basins down the eastern coast of Africa playing major roles in the continent's biogeography. Basins can function to group endemic communities while a giant, year-round river, such as the Congo, may act as a barrier that isolates species. Kingdon discussed how the interplay of geology, climate, adaptation, and dispersal led to the patterns of diversification we see in mammals today, with a predominant humid center-west biogeographic realm, and a drier longitudinal south-east realm. As the lead-editor of the six-volume Mammals of Africa ${ }^{29}$ and a lifetime spent in eastern Africa, Kingdon has unmatched first-hand knowledge of many of the continent's 1,111 species of mammals. He discussed his hypothesis of hominin origins in the eastern coastal forests, ${ }^{30}$ an idea that is receiving renewed attention. ${ }^{31}$ In this light, the new fossil sites from Gorongosa acquire special importance, as they sample Miocene woodlands/forests in a coastal paleoenvironment, ${ }^{9}$ and will allow for the testing of hypothesis about mammalian evolution in wooded coastal regions.

René Bobe provided an overview of early hominin environments. Bobe showed that paleontological sites reconstructed as highly dynamic and heterogeneous paleolandscapes are more likely to have a high abundance of hominins, as at Kanapoi around $4 \mathrm{Ma}, 32$ or a high diversity of hominins, as in the Koobi Fora Formation between 2.0 and $1.4 \mathrm{Ma}$, when up to four hominin species co-existed in a single basin. ${ }^{5}$ One of the key elements running through the discussions of early hominin paleoenvironments was the importance of water. Linda Marchant provided an insightful discussion of the role of water throughout our evolutionary history. Potable water is, and has been, a precious and often scarce resource, one that is fundamental 
to our survival. She drew from her extensive research on wild chimpanzees to illustrate how these primates may dig wells in dry streambeds, use leaf sponges, or suck on tubers for moisture. Chimpanzees also make use of a range of other fresh-water resources: they use tools to scoop algae and "fish" for fresh-water crabs. Early hominins may have relied on similar approaches to obtain water and forage at the water's edge. Marchant also discussed the role of hydro-refugia as a buffer against the increasingly unpredictable climates of the African late Miocene and Plio-Pleistocene. ${ }^{33}$ During periods of aridity, hominins (and other waterdependent mammals) would have stayed close to fresh-water refugia, and during wet periods they would have dispersed more widely. An appreciation of the critical role of water was also highlighted by Richard Wrangham, in a collaborative presentation with Andrew Cunningham, emphasizing that wet habitats are more important than often considered in human evolution. Wrangham outlined a model in which a Miocene ape inhabiting forests could have adapted to living outside the forests in environments similar those provided by the Okavango Delta, with year-round fruit trees and wet herbs. He further developed the delta hypothesis ${ }^{34}$ discussing how the abundant Okavango baboons provide a model of how a species like the chimpanzee could adapt to these habitats. Marc Stalmans commented that Gorongosa might also provide a model of a highly productive environment that could, in theory, support ape populations. Gorongosa today does not harbor any apes, but has three species of anthropoid primates: baboons, vervets, and Samango monkeys. Sarah Elton described how these three primates cooccur in many parts of southern Africa, and she traced back the evolutionary history of primate communities into the Pliocene. In her presentation, "Living together in complex environments", she discussed the roles of adaptation, niche partitioning, and ecological neutral theory in structuring primate communities. She emphasized that neutral processes may play an important role in structuring primate communities in complex habitats.

One of the ways in which early hominins adapted to complex environments was through the use of tools. Katarina Almeida-Warren discussed primate technology in the context of ecological and foraging landscapes. Based on her studies of wild chimpanzees as a point of reference, she argued that chimpanzees' reliance on percussive technologies produces a visible 
archeological record, in some ways akin to the earliest known hominin tools. ${ }^{35}$ Zeresenay Alemseged asked the question: did Australopithecus use tools? He provided answers based on the work at Dikika, Ethiopia, with evidence of the earliest stone-tool-modified bones dated to 3.4 Ma. ${ }^{36,37}$ Alemseged went on to discuss the morphological adaptations of $A$. afarensis, showing that the species had an ape-like scapula that reflected arboreal adaptations. ${ }^{38}$ Thus, it $^{2}$ is clear that early hominins evolved neither in closed canopy tropical rain forest nor in open savanna grasslands, but in intermediate, complex ecosystems composed of varying proportions of woodlands and grasslands usually close to permanent bodies of fresh water. Much of the data derives from key paleoanthropological sites along the East African Rift System, where variable topography, elevation, soil composition, temperature, and rainfall result in highly complex environments with high levels of biodiversity, both past and present. The study of living primates in these environments remains a key source of data and ideas for a better understanding of our own evolution.

\section{Conclusions}

This workshop brought to Gorongosa National Park a group of scholars that transcended traditional disciplinary boundaries to discuss primate adaptations to complex environments and their implications for understanding hominin evolution. The diverse tapestry of backgrounds amongst participants, and their openness to share their insights, produced lively discussions and rich exchanges of ideas. The workshop succeeded in generating future avenues for research, collaboration, and data sharing among primatologists, geneticists, and paleoanthropologists. Primatologists, for example, agreed on the importance of standardizing aspects of data collection so that they could carry out comparisons among widely separated sites. It is clear that we still have much to learn about the behavior of living primates, and that studies of primate ecology and behavior still have much to offer paleoanthropologists as they grapple with the fossil record. In turn, the time depth perspective of paleontologists can generate questions and hypothesis that can be tested with studies of living primates (e.g., what is the relationship between different levels of predation pressure and key aspects of primate 
behavior?). The workshop bridged in creative ways the past with the present, paleoanthropology with primate behavior, and paleontology with genetics. Having had this event in Gorongosa was of critical importance to bring a new generation of Mozambican students and colleagues in direct contact with top primatologists, primate geneticists, and paleoanthropologists. There was consensus among participants that this kind of meeting is essential for generating new ideas and enriching the context of research across anthropological disciplines.

\section{Presenters}

Scholars who gave presentations at the workshop: Susan Alberts (Duke University), Zeresenay Alemseged (University of Chicago), Dora Biro (University of Oxford), René Bobe (Gorongosa National Park and University of Oxford), Cristian Capelli (University of Oxford), Tongai Castigo (Gorongosa National Park), Alecia Carter (Université de Montpellier), Susana Carvalho (University of Oxford and Gorongosa National Park), Anthony Collins (Gombe Stream Research Centre, Jane Goodall Institute), Maria Joana Ferreira da Silva (CIBIO-InBIO, Universidade do Porto, and Cardiff University), Sarah Elton (Durham University), Julia Fischer (German Primate Center), Philippa Hammond (University of Oxford), Russell Hill (Durham University), Clifford Jolly (New York University), Jonathan Kingdon (University of Oxford), Lynn Lewis-Bevan (University of Oxford), Linda Marchant (Miami University), Felipe Martínez (Pontificia Universidad Católica de Chile), Jacinto Mathe (University of Coimbra), Thomas Püschel (University of Oxford), Marc Stalmans (Gorongosa National Park), Katarina Almeida-Warren (University of Oxford), Richard Wrangham (Harvard University), Dietmar Zinner (German Primate Center).

\section{Acknowledgments}

We are very thankful for the support of the Wenner-Gren Foundation for the workshop "New Perspectives on primate adaptations to complex environments and implications for early 
human evolution", as a grant awarded to S. Carvalho, R. Bobe, and F. Martínez. Holding this workshop in Gorongosa National Park was an important event for the park, and we are grateful for the support of the park's Warden, Pedro Muagura, the Director for Scientific Services, Marc Stalmans, as well as the members of the staff who kindly helped with the logistics of the new amphitheater. We are most grateful for the vision and continuous support of Greg Carr and the Carr Foundation. Megan Beardmore-Herd helped with much of the logistics and preparations before and during the workshop, as well as acting as the unofficial note-taker of the event. For thoughtful comments on earlier drafts of this manuscript, we thank Susan Alberts, Cristian Capelli, Alecia Carter, Anthony Collins, Sarah Elton, Julia Fischer, Russell Hill, Clifford Jolly, Jonathan Kingdon, Linda Marchant, Maria Joana Ferreira da Silva, Richard Wrangham, and Dietmar Zinner. RB is employed by the Gorongosa Project, a non-profit organization that manages conservation in Gorongosa National Park in partnership with the government of Mozambique.

\section{Figure captions}

Figure 1: Gorongosa National Park at the southern end of the East African Rift System. This map shows the location of the Miocene fossil sites and the park's extensive karstic system. Base image from https://lab.wildcamgorongosa.org/

Figure 2: Partial view of Lake Urema and its seasonally flooded grasslands. Woodlands are visible in the distance.

Figure 3: Gorongosa National Park baboon mother and offspring (Photo Bobe). There are 219 troops of baboons documented in the park.

Figure 4: Participants in the workshop "New perspectives on primate adaptations to complex environments and implications for early human evolution".

Figure 5: lion and waterbuck on the Urema floodplain, Gorongosa National Park. Lion populations in the park are becoming more abundant. Currently there are 146 lions in the park (as of December 2019). Photo credit: Gorongosa National Park. 
Figure 6: Wild dogs (or painted wolves) have been successfully reintroduced to Gorongosa National Park. Currently (December 2019) there are 52 wild dogs in the park. Photo: Brett Kuxhausen/Gorongosa Media.

\section{References}

[1] Tinley KL. 1977. Framework of the Gorongosa ecosystem. Pretoria: University of Pretoria. [2] Wilson EO. 2014. Landmark biodiversity survey. https://www.gorongosa.org/ourstory/science/landmark-biodiversity-survey: Gorongosa National Park.

[3] Stalmans M, Peel M, Gonçalves D. 2018. Aerial wildlife count of the Parque Nacional da Gorongosa, Mozambique, October 2018. Chitengo: Gorongosa National Park. 32 p.

[4] Martinez FI, Capelli C, Ferreira da Silva MJ, Aldeias V, Alemseged Z, Archer W, Bamford M, Biro D, Bobe R, Braun DR and others. 2019. A missing piece of the Papio puzzle: Gorongosa baboon phenostructure and intrageneric relationships. Journal of Human Evolution 130:1-20.

[5] Bobe R, Carvalho S. 2019. Hominin diversity and high environmental variability in the Okote Member, Koobi Fora Formation, Kenya. Journal of Human Evolution 126:91-105.

[6] Stalmans ME, Massad TJ, Peel MJS, Tarnita CE, Pringle RM. 2019. War-induced collapse and asymmetric recovery of large-mammal populations in Gorongosa National Park, Mozambique. PLOS ONE 14(3):e0212864.

[7] Pringle RM. 2017. Upgrading protected areas to conserve wild biodiversity. Nature 546(7656):91-99.

[8] Bouley P, Poulos M, Branco R, Carter NH. 2018. Post-war recovery of the African lion in response to large-scale ecosystem restoration. Biological Conservation 227:233-242.

[9] Habermann JM, Alberti M, Aldeias V, Alemseged Z, Archer W, Bamford M, Biro D, Braun DR, Capelli C, Cunha E and others. 2019. Gorongosa by the sea: First Miocene fossil sites from the Urema Rift, central Mozambique, and their coastal paleoenvironmental and paleoecological contexts. Palaeogeography, Palaeoclimatology, Palaeoecology 514:723-738.

[10] Fischer J, Higham JP, Alberts SC, Barrett L, Beehner JC, Bergman TJ, Carter AJ, Collins A, Elton S, Fagot $\mathrm{J}$ and others. 2019. Insights into the evolution of social systems and species from baboon studies. eLife 8:e50989.

[11] DeVore I, Washburn SL. 1964. Baboon ecology and human evolution. In: Howell FC, Bourlière F, editors. African ecology and human evolution. London: Methuen. p 335-367. [12] Altmann SA, Altmann J. 1970. Baboon ecology: African field research: Bibliotheca Primatologica.

[13] Strum SC, Mitchell W. 1987. Baboon models and muddles. In: Kinzey WG, editor. The evolution of human behavior: primate models. Albany, NY: State University of New York. p 87104.

[14] Jolly CJ. 2001. A proper study of mankind: analogies from the papionin monkeys and their implications for human evolution. Yearbook of Physical Anthropology 22:177-204. 
[15] Coleman BT, Hill RA. 2014. Living in a landscape of fear: the impact of predation, resource availability and habitat structure on primate range use. Animal Behaviour 88:165-173.

[16] Willems EP, Hill RA. 2009. Predator-specific landscapes of fear and resource distribution: effects on spatial range use. Ecology 90(2):546-555.

[17] Alberts SC, Altmann J. 2012. The Amboseli Baboon Research Project: 40 years of continuity and change. In: Kappeler PM, Watts DP, editors. Long-Term Field Studies of Primates. Berlin, Heidelberg: Springer Berlin Heidelberg. p 261-287.

[18] Carter AJ, Torrents Ticó M, Cowlishaw G. 2016. Sequential phenotypic constraints on social information use in wild baboons. eLife 5:e13125.

[19] Fischer J, Kopp GH, Dal Pesco F, Goffe A, Hammerschmidt K, Kalbitzer U, Klapproth M, Maciej P, Ndao I, Patzelt A and others. 2017. Charting the neglected West: The social system of Guinea baboons. American Journal of Physical Anthropology 162:15-31.

[20] Kamilar JM. 2006. Geographic variation in savanna baboon (Papio) ecology and its taxonomic and evolutionary implications. In: Lehman SM, Fleagle JG, editors. Primate biogeography. New York: Springer. p 169-200.

[21] Jolly CJ, Burrell AS, Phillips-Conroy JE, Bergey C, Rogers J. 2011. Kinda baboons (Papio kindae) and grayfoot chacma baboons (P. ursinus griseipes) hybridize in the Kafue river valley, Zambia. American Journal of Primatology 73(3):291-303.

[22] Rogers J, Raveendran M, Harris RA, Mailund T, Leppälä K, Athanasiadis G, Schierup MH, Cheng J, Munch K, Walker JA and others. 2019. The comparative genomics and complex population history of Papio baboons. Science Advances 5(1):eaau6947.

[23] Martínez F, Capelli C, Ferreira da Silva MJ, Aldeias V, Alemseged Z, Archer W, Bamford M, Biro D, Bobe R, Braun DR and others. 2019. A missing piece of the Papio puzzle: Gorongosa baboon phenostructure and intrageneric relationships. Journal of Human Evolution 130:1-20. [24] Zinner D, Groeneveld LF, Keller C, Roos C. 2009. Mitochondrial phylogeography of baboons (Papio spp.) - Indication for introgressive hybridization? BMC Evolutionary Biology 9(1):83. [25] Gilbert CC, Frost SR, Pugh KD, Anderson M, Delson E. 2018. Evolution of the modern baboon (Papio hamadryas): A reassessment of the African Plio-Pleistocene record. Journal of Human Evolution.

[26] Wildman DE, Bergman TJ, al-Aghbari A, Sterner KN, Newman TK, Phillips-Conroy JE, Jolly CJ, Disotell TR. 2004. Mitochondrial evidence for the origin of hamadryas baboons. Molecular Phylogenetics and Evolution 32(1):287-296.

[27] Elton S. 2008. The environmental context of human evolutionary history in Eurasia and Africa. Journal of Anatomy 212(4):377-393.

[28] Potts R. 2013. Hominin evolution in settings of strong environmental variability. Quaternary Science Reviews 73:1-13.

[29] Kingdon J, Happold DC, Butynski TM, Hoffmann M, Happold M, Kalina J, editors. 2013. Mammals of Africa. London: Bloomsbury Publishing.

[30] Kingdon J. 2003. Lowly origin: When, where, and why our ancestors first stood up. Princeton: Princeton University Press. 396 p.

[31] Joordens JCA, Feibel CS, Vonhof HB, Schulp AS, Kroon D. 2019. Relevance of the eastern African coastal forest for early hominin biogeography. Journal of Human Evolution 131:176-202. 
[32] Bobe R, Manthi FK, Ward CV, Plavcan JM, Carvalho S. 2020. The ecology of Australopithecus anamensis in the early Pliocene of Kanapoi, Kenya. Journal of Human Evolution:102717.

[33] Barboni D, Ashley GM, Bourel B, Arráiz H, Mazur J-C. 2019. Springs, palm groves, and the record of early hominins in Africa. Review of Palaeobotany and Palynology 266:23-41.

[34] Wrangham RW. 2005. The delta hypothesis: hominoid ecology and hominin origins. In: Lieberman DE, Smith RJ, Kelley J, editors. Interpreting the Past: Essays on Human, Primate and Mammal Evolution in Honor of David Pilbeam. Boston: Brill Academic Publishers. p 231-242. [35] Harmand S, Lewis JE, Feibel CS, Lepre CJ, Prat S, Lenoble A, Boes X, Quinn RL, Brenet M, Arroyo A and others. 2015. 3.3-million-year-old stone tools from Lomekwi 3, West Turkana, Kenya. Nature 521(7552):310-315.

[36] McPherron SP, Alemseged Z, Marean CW, Wynn JG, Reed D, Geraads D, Bobe R, Béarat HA. 2010. Evidence for stone-tool-assisted consumption of animal tissues before 3.39 million years ago at Dikika, Ethiopia. Nature 466(7308):857-860.

[37] Thompson JC, McPherron SP, Bobe R, Reed D, Barr WA, Wynn JG, Marean CW, Geraads D, Alemseged Z. 2015. Taphonomy of fossils from the hominin-bearing deposits at Dikika, Ethiopia. Journal of Human Evolution 86:112-135.

[38] Green DJ, Alemseged Z. 2012. Australopithecus afarensis scapular ontogeny, function, and the role of climbing in human evolution. Science 338(6106):514-517. 